\section{$\underset{\substack{\text { hommes } \\ \text { \& migrations }}}{ }$}

\section{Hommes \& migrations}

Revue française de référence sur les dynamiques

migratoires

1334 | 2021

Exposer le racisme et l'antisémitisme

\title{
Les musées face au défi démocratique
}

\section{Marie Poinsot}

\section{(2) OpenEdition \\ Journals}

\section{Édition électronique}

URL : https://journals.openedition.org/hommesmigrations/12803

DOI : 10.4000/hommesmigrations. 12803

ISSN : 2262-3353

\section{Éditeur}

Musée national de l'histoire de l'immigration

\section{Édition imprimée}

Date de publication : 1 juillet 2021

Pagination : 1

ISBN : 978-2-919040-58-2

ISSN : $1142-852 X$

\section{Référence électronique}

Marie Poinsot, «Les musées face au défi démocratique », Hommes \& migrations [En ligne], 1334 | 2021 , mis en ligne le 01 juillet 2021, consulté le 04 février 2022. URL : http://journals.openedition.org/ hommesmigrations/12803; DOI : https://doi.org/10.4000/hommesmigrations.12803 


\section{Édito}

\section{Les musées face au défi démocratique}

\author{
Marie Poinsot, \\ rédactrice en chef de la revue.
}

Nos sociétés sont balayées par des conflits violents autour de l'altérité sous toutes ses formes. Il y a urgence à lutter contre les phénomènes antisémites et racistes, à décloisonner les mobilisations identitaires et à articuler les mémoires, sans les hiérarchiser, sur des terrains communs. En tant qu'institutions publiques, les musées doivent préciser leur mission contre ces discriminations qui minent les sociétés. Le Musée national de l'histoire de l'immigration, en partenariat avec la Fondation Maison des sciences de l'Homme, a souhaité interroger d'autres musées à travers l'organisation du colloque international «Exposer le racisme et l'antisémitisme au Musée», les 6 et 7 mai 2021. Le dialogue proposé entre chercheurs et professionnels des musées comprenait un large panel d'institutions muséales en Europe et aux États-Unis. II a permis de réfléchir à la manière dont sont abordées ces questions, à la fois sensibles et complexes. Dans ce numéro, certaines contributions au colloque sont publiées sous forme de focus sur des expositions, d'autres sont synthétisées à partir de tables rondes thématiques. La revue remercie Mathias Dreyfuss et Régis Meyran pour avoir imaginé et coordonné cette publication.

\section{Des collections sur les racismes?}

La constitution de collections, au cœur de la mission des musées, ne va pas de soi quand elle porte sur les racismes. Face à l'ampleur des crimes commis dans l'histoire de nos sociétés, les musées ont longtemps choisi d'adopter une ignorance volontaire, rendue légitime par la difficulté à aborder ces histoires sans traces, lourdes de silences et d'absences ou bien guidée par la hantise de réactiver les préjugés racistes par le biais de l'exposition des œuvres racistes. Grâce à la production croissante des connaissances historiques sur l'esclavage, la colonisation, les génocides, etc., les musées sont mieux armés scientifiquement pour aborder ces périodes. L'élargissement des équipes curatoriales leur permet de présenter aux publics des collections à même de déconstruire les processus de fabrication historique des imaginaires et des rapports de domination qui génèrent la racialisation de certaines populations, leur exclusion voire leur extermination. Par ailleurs, les musées réexaminent les dossiers d'œuvres dont les inventaires témoignaient d'une vision partiale des populations représentées, propice aux injonctions discriminantes. Par le travail documentaire, ils cherchent désormais à réinscrire ces œuvres dans leur historicité - y compris dans leur cheminement au sein des collections - et à les exposer en précisant les singularités des populations et des territoires qu'elles représentent. Exposer et faire sens sont liés au profit d'une meilleure compréhension et appropriation des œuvres.

\section{Une démarche inclusive}

Dans ce numéro de la revue, les musées réfléchissent à leurs relations avec les populations dont leurs collections font l'objet. Ils montrent comment ils développent une démarche plus inclusive et participative en partageant les histoires de vie, les témoignages, les paroles de celles et ceux dont ils valorisent les cultures. Combattre les racismes au Musée passe aussi désormais par une approche des populations en tant qu'acteurs citoyens. Ainsi, contre l'invisibilité qui a prévalu souvent dans les expositions, les luttes sont intégrées dans les dispositifs scénographiques. Il s'agit d'interpeller les visiteurs et d'exposer les formes de résistance qui ont émergé, malgré les situations de répression extrêmes, mais dont la mémoire a parfois subi un redoutable effacement historique. Les artistes, à travers des résidences dans les musées, sont désormais invités à exprimer leur regard sur les collections et à identifier les résonances du passé qu'ils lisent dans le temps présent. Cette synergie polyphonique des contributeurs fait des expositions autant de laboratoires qui interrogent les modalités pratiques et symboliques des collectes, et qui suggèrent d'envisager les collections et leur exposition comme une aventure plurielle.

\section{Dynamiser les expositions}

Les musées ne se contentent plus d'exposer les représentations d'un passé raciste ou les preuves des crimes contre l'humanité. Ils élargissent l'offre muséale avec des activités pédagogiques et de médiation vers tous les publics, à travers la diffusion de catalogues et de dossiers pédagogiques. Ils multiplient les colloques, séminaires, ateliers participatifs, débats qui complètent la programmation ambitieuse de spectacles vivants, rencontres littéraires et projections de films. Ils proposent ainsi d'éclairer les collections à travers le déploiement d'autres imaginaires dont les écritures apportent d'autres témoignages sur les vécus intimes des pages sombres de nos démocraties. 